\title{
Hospital Length of Stay Reduction: A Long-Term Study
}

\author{
Ronald Lagoe $^{1 *}$, Barbara Drapola ${ }^{2}$, Mary Luziani' ${ }^{3}$, Louise Pernisi ${ }^{4}$ \\ ${ }^{1}$ Hospital Executive Council, Syracuse, NY, USA \\ ${ }^{2}$ Crouse Hospital, Syracuse, NY, USA \\ ${ }^{3}$ St. Joseph's Hospital Health Center, Syracuse, NY, USA \\ ${ }^{4}$ Upstate University Hospital-SUNY UMU, Syracuse, NY, USA \\ Email: "Hospexcl@cnymail.com
}

Received 1 July 2016; accepted 6 August 2016; published 9 August 2016

Copyright (C) 2016 by authors and Scientific Research Publishing Inc.

This work is licensed under the Creative Commons Attribution International License (CC BY). http://creativecommons.org/licenses/by/4.0/

(c) $\underset{\mathrm{EY}}{\mathrm{Br}}$ Open Access

\begin{abstract}
This study evaluated length of stay reduction for adult medicine and adult surgery in the combined hospitals of Syracuse, New York between 1998 and 2016. The study was based on the All Patients Refined Severity of Illness System. Through this approach, it controlled for changes in the degree of illness of hospital populations. The study data indicated that reductions in adult medicine and adult surgery stays in the Syracuse hospitals between 1998 and 2012 reduced the annual number of excess days compared with severity adjusted national averages by 49,000 , or an average daily census of $\mathbf{1 3 4 . 2}$. It appeared that the shift to reimbursement by discharges initiated by Medicare was a major cause of these reductions. The impact of this change was accompanied by length of stay reduction initiatives by the Syracuse hospitals, especially relating to long-term care. Between January-April 2012 and 2016, additional reductions brought the lengths of stay for adult medicine and adult surgery in the combined Syracuse hospitals close to the national average. The study suggested that remaining opportunities for length of stay reductions in Syracuse involved patients with high severity of illness and those discharged to nursing homes.
\end{abstract}

\section{Keywords}

Hospitalization, Hospital Lengths of Stay, Hospital Reimbursement, Nursing Homes

\section{Introduction}

In the United States, renewed interest is focusing on improving the efficiency and outcomes for health care. This interest is being generated by providers and payers of care [1] [2].

\footnotetext{
*Corresponding author.
} 
Historically, the implementation of the Prospective Payment System by Medicare in 1983 was probably the most important influence on the development of hospital efficiency. The change from payments per diem to payments per discharge shifted the focus of the acute care industry from keeping patients longer to discharging them sooner. Across the nation, this approach was adopted by Medicaid and insurance plans [3]-[6].

During the 1980s and 1990s, payments per discharge were responsible for the elimination of substantial volumes of inpatient days in United States hospitals. Some payers established reimbursement mechanisms to prevent premature hospital discharges; however, this did not change the movement toward shorter hospital stays [7] [8].

An important part of this development was an increase in the importance of long-term care services. Increased efficiency and shorter stays in hospitals required support from home health care and institutional long-term care for patients who required additional services [9].

In the twenty first century, increased payer attention on the need for system wide health care efficiency continued to develop. This attention has caused insurance plans such as Blue Cross and public payers such as Medicaid to become involved in regional and statewide efforts to improve hospital efficiency and outcomes.

Among health care providers, a recognition that efficient care is frequently the most effective care has been in development for some time. This recognition has been manifest in renewed efforts to develop post acute services and in initiatives to improve hospital outcomes such as post admission complications [10]-[12].

The connection between efficiency and outcomes in health care has drawn increased interest in the development of post hospital services with high severity of illness. This interest has led to the development of a new level of post acute services in some communities [13]-[15].

The impact of these developments has occurred in local health care systems throughout the nation. Because health care is a local function, the national impact is an aggregation of what occurs in local communities.

\section{Population}

This study described the development of acute hospital stays and efforts to address them in the metropolitan area of Syracuse, New York. This area includes three urban acute care facilities (2015 inpatient discharges in parentheses), Crouse Hospital (19,790 discharges), St. Joseph's Hospital Health Center (24,808 discharges), and Upstate University Hospital (28,236 discharges). These hospitals provide primary and secondary acute care services to an immediate area with a population of approximately 600,000 and tertiary services to the eleven county Central New York Health Service Area, with a population of 1,400,000.

Historically, the Syracuse hospitals have worked cooperatively to improve the efficiency and outcomes of acute care through their planning organization, the Hospital Executive Council. A number of these efforts have focused on reduction of inpatient hospital stays. Because the hospitals directly control only about 14 percent of the nursing home beds in the community, a number of these efforts have focused on long-term care services [16] [17].

\section{Method}

This study evaluated inpatient lengths of stay for adult medicine and adult surgery in the hospitals of Syracuse, New York between 1998 and 2016. During this period, these services accounted for 75 percent of discharges from the combined hospitals. The study focused on changes in inpatient stays and related utilization.

The study was carried out using patient specific data from each of the hospitals by the Hospital Executive Council. These data were obtained through Business Associate Agreements with each of the hospitals. The Council functions as a mechanism for the development of multihospital studies in the Syracuse metropolitan area.

The study data were analyzed using the All Patients Refined Diagnosis Related Group Severity of illness system developed by $3 \mathrm{M}^{\mathrm{TM}}$ Health Information Systems. This algorithm identified the severity of illness of each patient using the principal diagnosis, all secondary diagnoses, and demographic indicators such as age and gender. Levels of severity include Minor, Moderate, Major, and Extreme. In order to evaluate hospital lengths of stay, the algorithm identified comparison populations with the same distribution of patients by severity of illness.

Comparison populations were developed for use at the mean length of stay level and for mean stay differences converted to patient days. Through this approach, changes in the severity of illness of major service populations 
over time were identified and compared with changes in lengths of stay.

The initial component of the study focused on adult medicine and adult surgery stays for the combined Syracuse hospitals between January-December 1998 and 2014. This analysis identified numbers of discharges and mean lengths of stay for each service for January-December 1998, 2008, 2010, 2012, and 2014. The analysis also identified quantitative differences between each annual stay for the combined hospitals and the severity adjusted national average, as well as impact of this difference on patient days for the combined hospitals.

The time period of this component of the study included the long-term impact of the implementation of the change to reimbursement by discharges on the hospitals. This was the most important factor influencing the reduction of hospital stays in the community because it impacted the hospitals through reimbursement from all acute care payers.

In Syracuse, this change was also reflected in the development of internal efficiencies within the three hospitals and programs involving the hospitals and long-term care providers in the community. The community programs included the sharing of information concerning Difficult to Place patients by distribution of weekly community wide lists concerning these patients. They also included hospital initiatives to develop programs in nursing homes for specific types of Difficult to Place patients such as those who required long-term acute care services such as single intravenous antibiotics, extensive wound care, and specific high cost medications.

The second component of the study focused on adult medicine and adult surgery lengths of stay for the combined hospitals during the most recent period for which completely abstracted data were available, January-April 2012-2016. In order to adjust for seasonal variations in stays, four month periods were used for each year. This analysis also included numbers of discharges and mean lengths of stay for each major service and time period, as well as severity adjusted comparisons with stays for each time period at the unit level and through their impact on excess inpatient days. It involved comparisons with severity adjusted national averages developed by $3 \mathrm{M}^{\mathrm{TM}}$ Health Information Systems.

The third component of the study focused on identification of adult medicine and adult surgery lengths of stay in the combined hospitals for the most recent period available, January-April 2016 in order to identify remaining opportunities for length of stay reduction. This analysis involved two major indicators, severity of illness and discharge status. It involved comparisons with severity adjusted national averages developed by $3 \mathrm{M}^{\mathrm{TM}}$ Health Information Systems.

\section{Results}

The initial component of the study focused on lengths of stay for adult medicine and adult surgery in the Syracuse hospitals for January-December 1998-2014. Related data are summarized in Table 1.

This study data demonstrated that mean lengths of stay for adult medicine in the combined hospitals declined by 0.75 days, from 5.89 to 5.14 days between 1998 and 2012, before increasing to 5.45 days in 2014. The increase at the end of the period was related to the movement of approximately 1800 patients from inpatient to medical observation status brought about by a change in Medicare regulations concerning this subject.

The study data demonstrated that the reductions in adult medicine lengths of stay were paralleled by an increase in the severity of illness of the adult medicine population of the hospitals. This increase amounted to 0.56 days, or 12.6 percent, between 1998 and 2012. The shift of patients to medical observation in 2014 added another 4.5 percent to the severity adjusted comparison population.

The information in Table 1 demonstrated that the difference between the adult medicine mean length of stay for the combined Syracuse hospitals and the severity adjusted national average declined markedly, from 1.45 days in 1998 to 0.25 days in 2014. This was reflected in the reduction of the number of excess days from 36,653, an average daily census of 100.4, to 8355 days, an average daily census of 22.9.

The data in Table 1 demonstrated that mean lengths of stay for adult surgery in the combined Syracuse hospitals declined by 0.62 days, from 6.66 to 6.04 days, between January-December 1998 and 2014. This development did not include an increase in stays, such as that which occurred at the end of the period in adult medicine, because observation patients were not removed from this population.

The study data indicated that, as in adult medicine, the severity of illness of the inpatient population increased during this period. This increase amounted to 0.53 days, or 9.8 percent, during the time interval. This increase demonstrated that hospital stays declined as the severity of illness increased, resulting in an effective length of stay reduction of 1.15 days. 
Table 1. Inpatient mean lengths of stay, adult medicine and adult surgery, Syracuse Hospitals, 1998, 2008, 2010, 2012, 2014.

\begin{tabular}{|c|c|c|c|c|c|}
\hline & 1998 & 2008 & 2010 & 2012 & 2014 \\
\hline \multicolumn{6}{|l|}{ Adult Medicine } \\
\hline Number of Discharges & 25,278 & 28,565 & 32,221 & 35,274 & 33,421 \\
\hline Mean Length of Stay (Days) & 5.89 & 4.98 & 5.18 & 5.14 & 5.45 \\
\hline Severity Adjusted National Average & 4.44 & 4.68 & 4.84 & 5.00 & 5.20 \\
\hline Length of Stay Difference & 1.45 & 0.30 & 0.34 & 0.14 & 0.25 \\
\hline Patient Days Difference & $36,653.10$ & 8569.50 & $10,955.14$ & 4938.36 & 8355.25 \\
\hline \multicolumn{6}{|l|}{ Adult Surgery } \\
\hline Number of Discharges & 20,100 & 19,241 & 19,170 & 20,439 & 20,562 \\
\hline Mean Length of Stay (Days) & 6.66 & 6.23 & 6.25 & 6.04 & 6.04 \\
\hline Severity Adjusted National Average & 5.42 & 5.63 & 5.89 & 5.75 & 5.95 \\
\hline Length of Stay Difference & 1.24 & 0.60 & 0.36 & 0.29 & 0.09 \\
\hline Patient Days Difference & $24,924.00$ & $11,544.60$ & 6901.20 & 5927.31 & 1850.58 \\
\hline \multicolumn{6}{|c|}{$\begin{array}{l}\text { Adult medicine data exclude Diagnosis Related Groups concerning surgery, obstetrics, pediatrics, psychiatry, alcohol/substance abuse } \\
\text { treatment, rehabilitation, and all patients aged } 0 \text { - } 17 \text { years. }\end{array}$} \\
\hline \multicolumn{6}{|c|}{$\begin{array}{l}\text { Adult surgery data exclude Diagnosis Related Groups concerning medicine, obstetrics, pediatrics, psychiatry, alcohol/substance abuse } \\
\text { treatment, and all patients aged } 0 \text { - } 17 \text { years. }\end{array}$} \\
\hline
\end{tabular}

Source: Hospital Executive Council.

The information in Table 1 also demonstrated that, between January-December 1998 and 2014, the difference between the adult surgery length of stay for the combined Syracuse hospitals and the severity adjusted national average declined considerably, from 1.24 days in 1998 to 0.09 days in 2014. This was reflected in the reduction of the number of excess days from 24,924, an average daily census of 68.3, to 1850, an average daily census of 5.1 .

The length of stay data in Table 1 demonstrated the impact of a combination of trends on utilization at the community level. The most important of these was the continuing effect of the shift to reimbursement by discharge on hospital efficiency. This included all payers and most hospital revenue. In Syracuse, this trend was supported by a community wide study of hospital stays and planning for length of stay reduction.

In Syracuse, length of stay reduction was also affected by the development of additional capacity for home care and nursing homes by the hospitals and by the development of programs addressing patients with the longest stays. Programs developed by the hospitals to monitor the status of these patients and initiate programs in nursing homes for specific services also contributed to length of stay reduction during this period.

The second component of the study focused on adult medicine and adult surgery lengths of stay in the Syracuse hospitals between January-April 2012 and 2016. Relevant data are summarized in Table 2.

This information demonstrated that mean lengths of stay for adult medicine in the combined Syracuse hospitals decreased by 0.7 days, from 5.27 to 5.20 days between January-April 2012 and 2016. After the implementation of the Medicare medical observation regulations in 2013-2014, the mean adult medicine length of stay declined from 5.51 to 5.20 days.

Between January-April 2012 and 2016, the unit difference between the adult medicine hospital stay and the severity adjusted national average declined from 0.27 to 0.19 days, resulting in a decline in the number of excess patient days from 3093 to 2139. This left only 2139 excess adult medicine days, or an average daily census of 17.8 in the combined hospitals.

This decline demonstrated that the impact of provider efforts to reduce stays in the Syracuse hospitals and continued payer incentives for length of stay reduction offset the impact of the medical observation regulations. They included the implementation of a wide ranging effort to reduce stays throughout one of the hospitals and 
Table 2. Inpatient mean lengths of stay, adult medicine and adult surgery, Syracuse Hospitals, January-April 2012, 2014, 2016.

\begin{tabular}{lccc}
\hline & 2012 & 2014 & 2016 \\
\hline Adult Medicine & & & 11,259 \\
Number of Discharges & 11,456 & 5.20 & 5.01 \\
Mean Length of Stay (Days) & 5.27 & 5.51 & 0.19 \\
Severity Adjusted National Average & 5.00 & 5.27 & 2139.21 \\
Length of Stay Difference & 0.27 & 0.24 & 7554 \\
Patient Days Difference & 3093.12 & 2573.28 & 5.94 \\
Adult Surgery & & 6538 & 6.12 \\
Number of Discharges & 6654 & 6.03 & -0.18 \\
Mean Length of Stay (Days) & 6.08 & 6.02 & -1359.72 \\
Severity Adjusted National Average & 5.76 & 0.01 & 65.38
\end{tabular}

Adult medicine data exclude Diagnosis Related Groups concerning surgery, obstetrics, pediatrics, psychiatry, alcohol/substance abuse treatment, rehabilitation, and all patients aged 0 - 17 years.

Adult surgery data exclude Diagnosis Related Groups concerning medicine, obstetrics, pediatrics, psychiatry, alcohol/substance abuse treatment, and all patients aged 0 - 17 years.

Source: Hospital Executive Council.

the initiation of Complex Care Programs by the hospitals and area nursing homes during 2015 for services including multiple intravenous antibiotics, combinations of expensive medications, and one on one psychiatric care.

The information in Table 2 demonstrated that mean lengths of stay for adult surgery in the combined hospitals declined from by 0.14 days, from 6.08 to 5.94 days, between January-April 2012 and 2016. This reflected a continuation of the decline in stays that occurred between 1998 and 2010.

Between January-April 2012 and 2016, the difference between the adult surgery length of stay for the combined hospitals and the severity adjusted national average stay changed from an excess of 0.32 days to a savings of 0.18 days, a savings of one half day. This caused the adult surgery patient days difference to change from an excess of 2129 days, an average daily census of 17.7, to a savings of 1359 days, an average daily census savings of 11.3 .

The continued decline in adult surgery lengths of stay during this period resulted from a number of initiatives. They included a wide ranging effort to reduce stays at the hospital with the largest inpatient surgery volume and the initiation of Complex Care Programs by the hospitals and area nursing homes during 2015 for services including multiple intravenous antibiotics and extensive wound care with medications.

The third component of the study focused on adult medicine and adult surgery lengths of stay in the combined Syracuse hospitals between January-April 2016 by severity of illness and discharge status. Relevant data are summarized in Table 3.

This information demonstrated that within adult medicine, lengths of stay for the combined patients at Minor severity of illness were at the severity adjusted national average, while patients at Moderate, Major, and Extreme severity stayed longer, generating more than 2100 excess patient days.

The data indicated that the differences between hospital stays and national averages increased with rising severity of illness to more than one half day for Extreme patients.

For adult surgery patients, stays for patients in the combined hospitals were more than one day shorter than national averages for patients at Minor and Moderate severity, saving more than 8700 patient days. Stays were longer than the national averages for patients at Major and Extreme severity, generating more than 7400 excess patient days. For patients at Extreme severity, the difference was more than 10 days. 
Table 3. Inpatient mean lengths of stay, adult medicine and adult surgery, Syracuse Hospitals, January-April 2016.

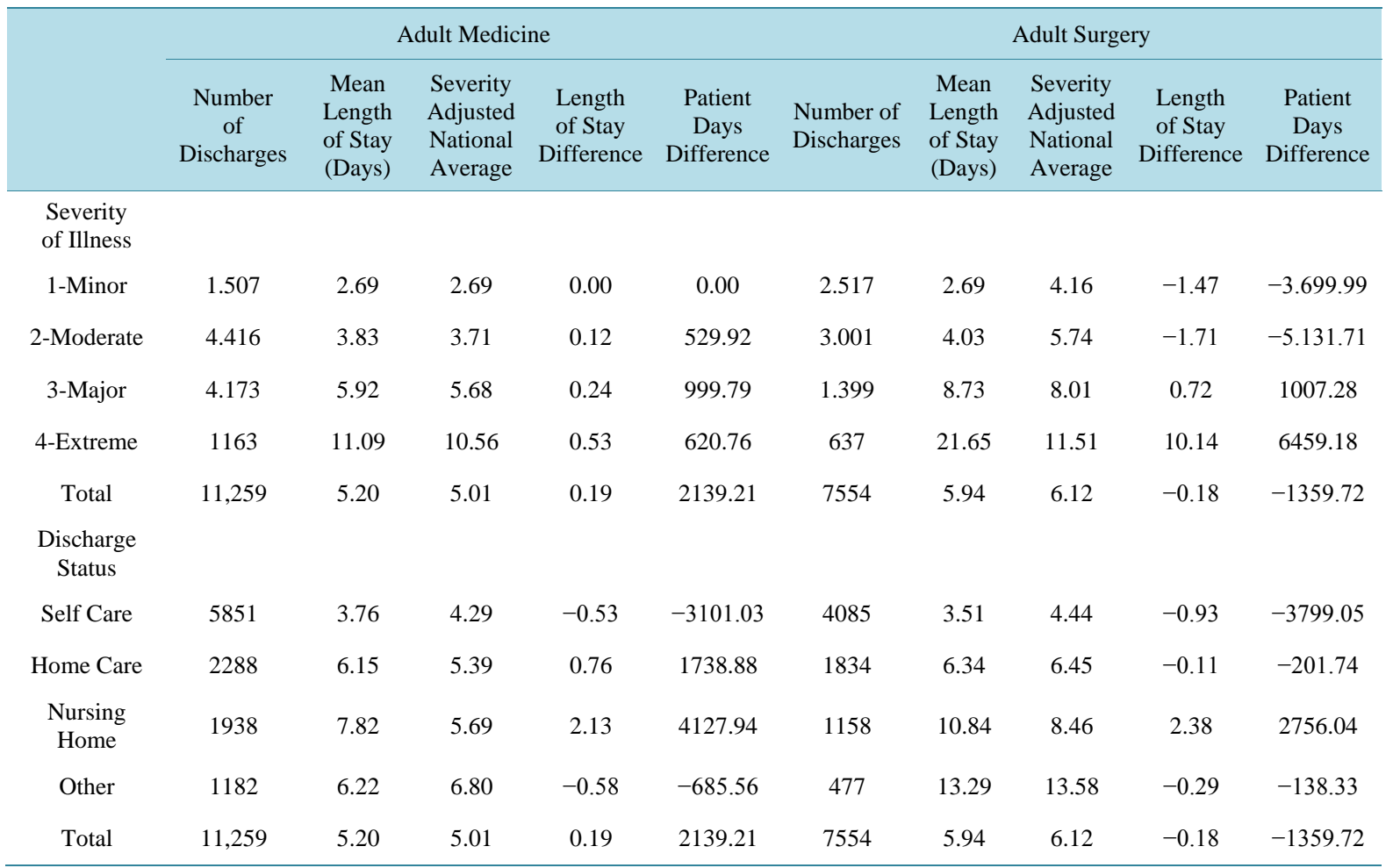

For adult medicine, the data demonstrated that stays for the combined hospitals were shorter than severity adjusted national averages for patients discharged with self care and with deaths and transfers, saving more than 3700 patient days. Stays for discharges to long-term care services were longer than the national averages, generating more than 5800 excess patient days. Stays for discharges to nursing homes were more than 2 days longer.

For adult surgery, stays for patients discharged with self care, home care, and deaths and transfers had stays shorter than severity adjusted national averages, saving more than 4000 patient days. Stays for patients discharged to nursing homes averaged more than 2 days longer than severity adjusted national averages producing more than 2700 excess days.

This information demonstrated that, although the Syracuse hospitals had made considerable progress in length of stay reduction between 1998 and 2016, opportunities for additional initiatives remained. These included patients with relatively high severity of illness and those discharged to nursing homes. The data suggested that many of these extended stays were generated by long-term acute patients who remained in hospitals because of the lack of alternative services in the community. These conclusions were suggested by the length of stays required in hospitals for both adult medicine and adult surgery patients discharged to nursing homes.

\section{Discussion}

This study evaluated length of stay reduction for the combined hospitals of Syracuse, New York during an extended period comprising 18 years. It identified hospital stays for adult medicine and adult surgery that occurred during this period and the developments that produced them.

The study was based on the All Patients Refined Diagnosis Related Group severity of illness system developed by $3 \mathrm{M}^{\mathrm{TM}}$ Health Information Systems. This system identified lengths of stay based on comparisons with national populations with the same severity of illness. Through this approach, it controlled for changes in the degree of illness of hospital populations. This was an important development in the use of hospital inpatient data.

The study data indicated that substantial reductions in adult medicine and adult surgery stays occurred in the Syracuse hospitals between 1998 and 2012. These declines reduced the number of excess patient days compared with the severity adjusted national average by more than 31,000 for adult medicine and more than 18,000 for 
adult surgery.

It appeared that the shift from reimbursement by patient days to reimbursement by discharges was a major cause of these reductions. This shift was initiated by Medicare during the 1980s and followed by other payers, but its impact on hospitals at the community level developed over time. Additional factors, such as the introduction of new technologies including robotic procedures, had contributed to reductions in stays for adult surgery.

The experience of the Syracuse hospitals indicated that the impact of the change in inpatient reimbursement was accompanied by hospital length of stay reduction initiatives. These included hospital efforts to address stays for patients discharged to long-term care, such as the development of additional home care and nursing home capacity. It also included the initiation of community wide efforts between hospitals and nursing homes to identify Difficult to Place patients in hospitals and development of long-term acute care services for these patients in nursing homes.

The study data and the experiences of the Syracuse hospitals indicated that, since 2012, the rate of reductions in hospital stays has slowed as stays have become shorter, generating more focused efforts to address this subject. Between January-April 2012 and 2016, adult medicine stays have approached severity adjusted national averages and adult surgery stays have become shorter. These developments have been supported by substantial efforts by hospital administrators to focus resources on length of stay reduction and the development of programs with local nursing homes to address Complex Care services, such as multiple intravenous medications, extensive wound care, and mental health.

In recent years, efforts to reduce stays have also been supported by initiatives to improve the outcomes of care. These have included efforts to reduce inpatient complications, which are frequently associated with long stays.

The study suggested that remaining opportunities for length of stay reduction in the Syracuse hospitals involved patients with high severity of illness and those discharged to nursing homes. Addressing these needs will require initiatives that focus on remaining populations with extended stays, such as patients who require longterm acute care and complex care. In many communities, the initiative for development of these programs will need to come from hospitals. They are frequently the only providers with major interests in serving the needs of these patients. The development of services for these populations will require increasing levels of cooperation among hospitals, as well as between acute care and long-term care providers at the community level.

\section{References}

[1] Dentzler, S. (2011) Urgent Measures for an Old Problem. Health Affairs, 30, 1626. http://dx.doi.org/10.1377/hlthaff.2011.0961

[2] Marcus, A. (2009) Bending the Curve: The Twists and Turns. Health Affairs, 28, 1256-1258. http://dx.doi.org/10.1377/hlthaff.28.5.1256

[3] Friedman, B., De La Mare, J., Andrews, R. and McKenzie, D.H. (2002) Practical Options for Estimating the Costs of Hospital Stays. Journal of Health Care Finance, 29, 1-13.

[4] Cushing, W.T. (2004) Extra Hospital Days Can Cost You Plenty. Medical Economics, 81, 83.

[5] Fong, T. (2004) Medicaid under the Knife? Congress Considering Funding Cuts in Program? Modern Healthcare, 34, 6-7.

[6] Hoadley, J.F., Cunningham, P. and McHugh, M. (2004) Popular Medicaid Programs Do Battle with State Budget Pressures: Perspectives from Twelve States. Health Affairs, 23, 143-154. http://dx.doi.org/10.1377/hlthaff.23.2.143

[7] Shah, B.R., Reed, S.D., Francis, J., Ridley, D.B. and Schulman, K.A. (2003) The Cost of Inefficiency in U.S. Hospitals, 1985-1987. Journal of Health Care Finance, 30, 1-9.

[8] Pena, A.D. and Ndiyae, M. (2002) Developing Hospital Efficiency Cost Control Measures. World Hospitals and Health Services, 38, 41-43.

[9] Marek, K.D. and Rantz, M.J. (2000) Aging in Place: A New Model for Long Term Care. Nursing Administration Quarterly, 24, 1-11. http://dx.doi.org/10.1097/00006216-200004000-00003

[10] Weil, A.R. (2015) Hospital Cost and Quality. Health Affairs, 34, 1263. http://dx.doi.org/10.1377/hlthaff.2015.0786

[11] Skinner, J., Chandra, A., Goodman, D. and Fisher, E.S. (2009) The Elusive Connection between Health Care Spending and Quality. Health Affairs, 28, w119-w123. http://dx.doi.org/10.1377/hlthaff.28.1.w119

[12] Fuller, R.L., McCullough, E.C., Bao, M.Z. and Averill, R.F. (2009) Estimating the Costs of Potentially Preventable Hospital Acquired Complications. Health Care Financing Review, 30, 17-32.

[13] Gawande, A.A. (2011) The Hot Spotters: Can We Lower Costs by Getting the Neediest Patients Better Care? New 
Yorker.

[14] Hong, C.S., Siegel, A.L. and Ferris, T.G. (2014) Caring for High Need, High Cost Patients: What Makes for a Successful Care Management Program? Commonwealth Fund, New York. http://dx.doi.org/10.15868/socialsector.25007

[15] Johnson, T.L., Rinehart, D.J., Durfee, J., Brewer, D., Batal, H., Blum, J., Oronce, C.J. and Melinkovich, P. (2015) For Many Patients Who Use Large Amounts of Health Services, the Need Is Intense Yet Temporary. Health Affairs, 34, 1312-1323. http://dx.doi.org/10.1377/hlthaff.2014.1186

[16] Lagoe, R.J., Westert, G.P., Kendrick, K., Morreale, G. and Mnich, S. (2005) Managing Hospital Length of Stay Reduction: A Multihospital Approach. Health Care Management Review, 30, 89-92. http://dx.doi.org/10.1097/00004010-200504000-00002

[17] Lagoe, R., Pasinski, T., Kronenberg, P., Quinn, T. and Schaengold, P. (2006) Linking Health Services at the Community Level. Canada Healthcare Quarterly, 9, 60-65. http://dx.doi.org/10.12927/hcq..18229

\section{Submit or recommend next manuscript to SCIRP and we will provide best service for you:}

Accepting pre-submission inquiries through Email, Facebook, LinkedIn, Twitter, etc. A wide selection of journals (inclusive of 9 subjects, more than 200 journals)

Providing 24-hour high-quality service

User-friendly online submission system

Fair and swift peer-review system

Efficient typesetting and proofreading procedure

Display of the result of downloads and visits, as well as the number of cited articles

Maximum dissemination of your research work

Submit your manuscript at: http://papersubmission.scirp.org/ 